\title{
Determination of Selected Essential and Non-Essential Metals in Three Types of Teff (Eragrostis tef) Cultivated in Southern Ethiopia
}

\author{
Abebe Habte, Alemu Lelago*, Mesfin Bibiso Doda, Camerun Kastro Kanido* \\ Department of Chemistry, College of Natural \& Computational Science, Wolita Sodo University, Wolita Sodo, Ethiopia \\ Email: *lelagoalemu@gmail.com, mefbab2009@gmail.com, ${ }^{*}$ castro2019came@gmail.com
}

How to cite this paper: Habte, A., Lelago, A., Doda, M.B. and Kanido, C.K. (2020) Determination of Selected Essential and Non-Essential Metals in Three Types of Teff (Eragrostis tef) Cultivated in Southern Ethiopia. Journal of Agricultural Chemistry and Environment, 9, 255-275. https://doi.org/10.4236/jacen.2020.94020

Received: August 16, 2020

Accepted: November 7, 2020

Published: November 10, 2020

Copyright () 2020 by author(s) and Scientific Research Publishing Inc. This work is licensed under the Creative Commons Attribution International License (CC BY 4.0).

http://creativecommons.org/licenses/by/4.0/

(c) (i) Open Access

\begin{abstract}
Teff (Eragrostis tef) is used to supply staple food "injera" for many Ethiopians. The present study was aimed toward determining the extent of selected metals that can exist in three types of teff cultivated in selected districts of southern Ethiopia. The level of those metals was determined by flame atomic absorption spectrometry. The optimized wet digestion procedure was evaluated employing a spiking method and an acceptable percentage recovery of $(91.1 \%-108.9 \%)$ has been obtained for metals in the teff. Oven dried $1 \mathrm{~g}$ of teff samples were digested using $5 \mathrm{~mL}$ of $\mathrm{HNO}_{3}$ and $1 \mathrm{~mL}$ of $\mathrm{HClO}_{4}$ at $300^{\circ} \mathrm{C}$ for 3 hours. The result indicated that the mean concentration of metals (in $\mathrm{mg} / \mathrm{kg}$ dry weight basis) in teff samples were found to be from 1206.9 to 1768.9 of $\mathrm{Ca}, 2463.9$ to 2554.7 of $\mathrm{Mg}, 82.6$ to 109.9 of Na, 2879 to 3075 of K, 207.4 to 239.5 of Fe, 55.9 to 100.4 of $\mathrm{Mn}, 27.1$ to 87.1 of $\mathrm{Zn}, 5.4$ to $45.5 \mathrm{of} \mathrm{Cu}$ and 0.118 to 0.130 of $\mathrm{Pb}$ respectively. However, $\mathrm{Cd}$ is below the method detection limit. A statistical analysis of variance revealed that there was a significant difference $(p \leq 0.05)$ between the mineral content in three teff types and teff from the three districts. Red teff had higher essential metal contents except $\mathrm{Cu}$ followed by brown teff. Strong positive correlation was recognized between $\mathrm{Mg}$ with $\mathrm{Ca}$ and $\mathrm{K}$, the rest have moderate or weak correlation. Further study has been done on the mineral contents of similar variety or three types of teff with the soil analysis from different locations.
\end{abstract}

\section{Keywords}

Teff, Essential Metal, Non-Essential Metals, Wet-Digestion, Flame Atomic Absorption Spectrophotometer (FAAS)

\section{Introduction}

Teff (Eragrostis tef (Zucc.) Totter) is a tropical cereal crop. It had been believed 
that the origin and diversification of Eragrostis tef are Ethiopia, but recently it has been used in different parts of the world due to its attractive nutritional profiles as grains for human consumption and as forage for animal feed [1] [2] [3]. Teff is greatly valued by farmers and consumers in Gamogofa, Gurage, Hadiya, Kembata-Tembaro, Halaba and kaffa which are the main producing zones in Southern Nations, Nationalities, and Peoples Regional State (SNNPRS) [4]. Teff varieties were adaptable to the ecological conditions in altitudes that range from near sea level to 3000 m.a.s.l and are often grown in an environment unfavorable for many cereals, but in Ethiopia the best performance occurs between 1100 and 2950 m.a.s.l [5]. It grows in dry as well as water-logged soils, can tolerate anoxic situations better than other cereals, and is resistant to many pests and diseases [6].

Teff is an important food security crop in Ethiopia and East African Highlands [7]. In Ethiopia, the crop occupies over 2.8 million hectares equivalent to $25 \%-30 \%$ of the entire area covered by cereals [8]. It is a daily food staple for more than 60 million people in the country. "Injera" is a major food staple, and provides approximately two thirds of the diet in Ethiopia [9].

Teff grain has been begun to be utilized in mixtures with soybean, chickpea and other grains in the baby food industry due to its high mineral content [10]. Non-teff consumers have a lower level of hemoglobin, and hookworm anemia develops in non-teff eaters if they are infected with hookworm. On the other hand, since teff eaters have higher levels of hemoglobin in their blood, they do not suffer from hookworm anemia even when infested. Malaria is also frequently found in the groups with lower hemoglobin levels. Moreover, consuming teff prevents the anemia related to pregnancy [11].

The quantity of teff produced worldwide is increasing rapidly due to the plant's popularity as an especially nutritious grain and as high quality straw [7]. The grain features a very high protein, carbohydrate, fat, vitamin A and C, fiber, Thiamin, Riboflavin, Niacin, and essential minerals like Calcium, Iron, Magnesium, Manganese, Phosphorus, Potassium, Sodium, Zinc, Copper, Chloride and Chromium [12] [13] [14].

Various kinds of cereal crops serve as the main food item for peoples in the world due to their diverse ecological, environmental and preparation custom differences. Teff is a fine stemmed, tufted annual grass like cereal crop, preferred over other cereal crops in Ethiopia. It is estimated to feed millions of people and is extremely important for peoples comprising rural producers, processors and consumers in Ethiopia [15].

The knowledge on the importance of trace, minor and major elemental content analysis of food for human health has generated interest in different food preparation practices and hence, the necessity for its quantitative and qualitative determination of cereal crops is important for both producers and consumers [16].

Relative to common cereal crops such as wheat, rice and sorghum, little is 
known about the nutritional composition and potential health benefits of teff. In Ethiopia, there is a prolonged consideration of teff grain as low nutritional value because of limited information in this regards. However, there has been a growing research interest globally by the nutritionist and food scientists due to its gluten-free nature, nutritional composition and accelerated teff-based products. Studies conducted on the nutritional composition and health benefits of teff are limited and cannot take into account the differences in teff varieties and growing conditions. A few studies so far confirmed that teff has excellent nutritional profiles and suggested as considerable potential to be a functional food for health promotion and disease prevention [3].

Most of the researches conducted on teff are associated with genetic variety improvement and adaptability. No literature is found on the determination of essential and non-essential metals in teff types with respect to area of cultivation. Therefore, studying the content of essential and non-essential metals in different sorts of teff is extremely important in dietary applications of food. Hence, the present study aimed toward determining the level of selected essential and non-essential metals ( $\mathrm{K}, \mathrm{Mg}, \mathrm{Ca}, \mathrm{Na}, \mathrm{Mn}, \mathrm{Zn}, \mathrm{Fe}, \mathrm{Cu}, \mathrm{Pb}$ and $\mathrm{Cd}$ ) that can exist in three types of teff mainly used by the peoples of study area in order to ensure health benefits of individuals. Furthermore, the results of this study may help to identify the difference in mineral content of teff with area of cultivation.

\section{Experimental}

\section{Equipment and apparatuses}

Digital balance (Mettler Toledo, Model AG204 Switzerland) with \pm 0.0001 precision was used for weighing the samples. The washed teff samples were dried using a drying oven (DIGITHEAT, Spain). A high speed universal disintegrator was used to grind and powder the dried teff samples. A volumetric flask $(100 \mathrm{ml})$ with grounded glass fitted with condenser was employed in digesting the sample on Kjeldahl heating apparatus (Gallenhamp, England). A 50, 100 and $250 \mathrm{ml}$ volumetric flask were used during dilution of sample and preparation of metal standard and infusion solutions. Reagents, sample solutions and standard solutions of metals have been measured using measuring cylinders, pipettes, micropipettes (Dragonmed, 1 - $10 \mu \mathrm{l}, 100-1000 \mu \mathrm{l}$, Shangai, China). A refrigerator (Hitachi, Tokyo, Japan) was used to keep the digested sample before analysis. Buck Scientific Model 210VGP FAAS (East Norwalk, USA) equipped with deuterium arc background correctors was used for analysis of the metals $(\mathrm{K}, \mathrm{Mg}, \mathrm{Ca}$, $\mathrm{Na}, \mathrm{Mn}, \mathrm{Zn}, \mathrm{Fe}, \mathrm{Cu}, \mathrm{Pb}$ and $\mathrm{Cd}$ ) using air- $\mathrm{C}_{2} \mathrm{H}_{2}$ flame [17] [18].

\section{Reagents and Chemicals}

Analytical grade reagents and standards were used in the analysis. Digestion of teff samples was done using $\mathrm{HNO}_{3}(69 \%-72 \%)$ and $\mathrm{HClO}_{4}(70 \%)$ (Research-Lab Fine Chem. Industries Mumbai 400002 (India)). Hydrated Lanthanum nitrate, $\mathrm{La}\left(\mathrm{NO}_{3}\right)_{3} \cdot 6 \mathrm{H}_{2} \mathrm{O} 98 \%$ (BDH Chemicals Ltd, Poole, England) was used to avoid the precipitation of $\mathrm{Ca}$ and $\mathrm{Mg}$ ions in the form of phosphates and 
sulfates. Stock standard solutions of $1000 \mathrm{mg} / \mathrm{L}$, in $2 \% \mathrm{HNO}_{3}$, of the metals $\mathrm{K}$, $\mathrm{Mg}, \mathrm{Ca}, \mathrm{Na}, \mathrm{Mn}, \mathrm{Zn}, \mathrm{Fe}, \mathrm{Cu}, \mathrm{Pb}$ and $\mathrm{Cd}$ were used for the preparation of calibration standards of each metal and in the spiking experiments. The working standards of each metal were prepared from intermediate standard solutions. Deionized water (Milli-Q) was used throughout the experiments for sample preparation, dilution, and rinsing apparatus prior to analysis and during analysis [7] [19].

\section{Description of Study Area}

The study was conducted in Gurage (Abeshege), Hadiya (Soro) and Halaba (Wera) zones, one district from each zone, of SNNPRS Ethiopia. The climatic condition and location of the study area are shown in Table 1 and Figure 1.

\section{Sample Collection}

White, brown and red teff samples were collected in polyethylene plastic bags from Soro, Abeshege and Wera districts of Southern Ethiopia which are known cultivating teff in large amount. To draw the representative sample from each

Table 1. Description of climatic condition of the study area.

\begin{tabular}{ccccccc}
\hline District & Latitude & Longitude & $\begin{array}{c}\text { Elevation } \\
(\mathrm{m})\end{array}$ & $\begin{array}{c}\text { Annual } \\
\text { Temp }\left({ }^{\circ} \mathrm{C}\right)\end{array}$ & $\begin{array}{c}\text { Annual Rain } \\
\text { fall }(\mathrm{mm})\end{array}$ & Reference \\
\hline Abeshege & $8^{\circ} 27^{\prime} 30^{\prime \prime} \mathrm{N}$ & $38^{\circ} 10^{\prime} 50^{\prime \prime} \mathrm{E}$ & $1001-2000$ & 21.25 & $801-1400$ & {$[20]$} \\
Soro & $7^{\circ} 30^{\prime \prime} \mathrm{N}-7^{\circ} 43^{\prime \prime} \mathrm{N}$ & $37^{\circ} 35^{\prime} \mathrm{E}-38^{\circ} 05^{\prime} \mathrm{E}$ & $1454-2850$ & 19 & 1260 & {$[21]$} \\
Wera & $7^{\circ} 17^{\prime \prime} \mathrm{N}$ & $38^{\circ} 06^{\prime} \mathrm{E}$ & $1554-2149$ & 18 & $857-1085$ & {$[22][23]$} \\
\hline
\end{tabular}

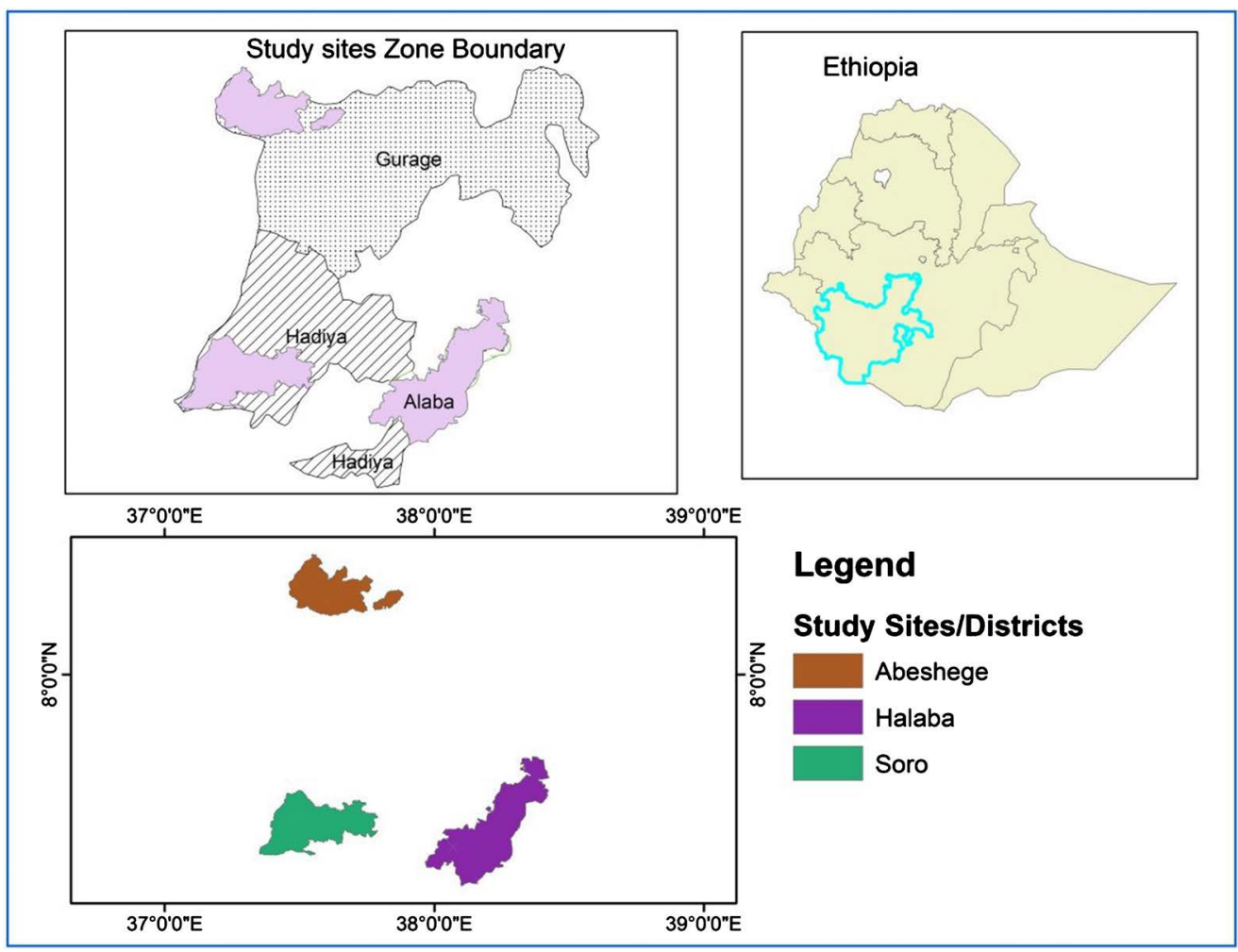

Figure 1. Map of the study area. 
sampling sites, four sub samples for every sort of teff (200 g each) were purchased from open market of those selected district towns, about 200 gm of teff sub sample for every type was collected from the bag of four teff producers that come from different sites of the chosen district, then the sub samples were pooled and mixed together for every variety. A total of $800 \mathrm{~g}$ were collected from each of the above selected districts per sort of samples. The sample size was reduced to about $200 \mathrm{~g}$ by coning and quartering process for every sort of sample. For each kind, nearly $50 \mathrm{~g}$ of sample was taken for the analysis [7] [19].

\section{Sample Preparation}

The husk and other light and heavy contaminants were removed from the samples by siftings, winnowing and sieving to make sure it had been free from chaffs, dust and other impurities. The samples were washed in a plastic bag by vigorous up and down shaking first with water as repeatedly until all dust was removed and then three times with distilled water [7]. Having a constant mass, the washed teff samples were dried in universal hot air oven at $105^{\circ} \mathrm{C}$ for 5 hours before digestion so as to express the result in terms of dry mass basis. The mineral content of samples should not be affected at a drying temperature [14]. The dried teff samples were powdered using high speed universal disintegrator until it feels smooth to the touch. Nine samples with $1 \mathrm{~g}$ aliquot (three from each bulk sample) were taken for final digestion.

\section{Optimization of the Working Procedure}

Optimum working procedure has been developed so as to urge a reliable result from an analytical experiment. Thus, to prepare a clear and colorless sample solution that was suitable for the analysis using FAAS, different working procedures for the digestion of teff samples were assessed using variable parameters to the mixtures of $\mathrm{HNO}_{3}$ and $\mathrm{HClO}_{4}$ acids like volume of the acids mixture, digestion time and digestion temperature. The optimized procedure was selected depending upon the clearness of the ultimate digests obtained as of less digestion time, less reagent volume consumption and ease [24] [25] [26].

Accordingly, ten trials were tested for digestion of the teff samples. The optimal digestion procedure chosen was the one that needs $3 \mathrm{hr}$ for complete digestion of $1 \mathrm{~g}$ of teff powders, with $5 \mathrm{ml}$ of $70 \% \mathrm{HNO}_{3}$ and $1 \mathrm{ml}$ of $70 \% \mathrm{HClO}_{4}$ (Table 2) were used throughout the analysis.

\section{Instrument Operating Conditions}

Secondary standard solutions containing $10 \mathrm{mg} / \mathrm{L}$ were prepared in $100 \mathrm{ml}$ volumetric flask from the atomic absorption spectroscopy standard stock solutions that contained $1000 \mathrm{mg} / \mathrm{L}$ which was prepared from soluble salts of each metal. These secondary standards were diluted with deionized water to get five working standards for every metal of interest (Table S2). Then, the metal contents of sample ( $\mathrm{K}, \mathrm{Mg}, \mathrm{Ca}, \mathrm{Na}, \mathrm{Mn}, \mathrm{Zn}, \mathrm{Fe}, \mathrm{Cu}, \mathrm{Pb}$ and $\mathrm{Cd}$ ) were analyzed by FAAS equipped with deuterium arc background corrector and standard air-acetylene flame system using external calibration curve after the parameters (burner and lamp alignment, slit width and wavelength) were optimized for 
Table 2. Conditions tested for the optimization of digestion procedures for $1 \mathrm{~g}$ of teff flour samples.

\begin{tabular}{cccccc}
\hline Trial & Regent used & $\begin{array}{c}\text { Volume } \\
\text { Ratio }(\mathrm{ml})\end{array}$ & $\begin{array}{c}\text { Temp } \\
\left({ }^{\circ} \mathrm{C}\right)\end{array}$ & $\begin{array}{c}\text { Digestion } \\
\text { Time }(\mathrm{hr})\end{array}$ & Observation \\
\hline 1 & $\mathrm{HNO}_{3}: \mathrm{HClO}_{4}$ & $4: 8$ & 200 & $4: 25$ & Clear Light yellow \\
2 & $\mathrm{HNO}_{3}: \mathrm{HCLO}_{4}$ & $5: 2$ & 210 & $4: 35$ & Deep yellow with suspension \\
3 & $\mathrm{HNO}_{3}: \mathrm{HClO}_{4}$ & $3: 2$ & 210 & $3: 05$ & Deep Yellow \\
4 & $\mathrm{HNO}_{3}: \mathrm{H}_{2} \mathrm{O}_{2}$ & $10: 1$ & 210 & $3: 15$ & Clear yellow \\
5 & $\mathrm{HNO}_{3}: \mathrm{HClO}_{4}$ & $4: 8$ & 240 & $4: 00$ & Clear Colorless \\
6 & $\mathrm{HNO}_{3}: \mathrm{HClO}_{4}$ & $5: 8$ & 240 & $4: 10$ & Clear Light yellow \\
7 & $\mathrm{HNO}_{3}: \mathrm{HClO}_{4}: \mathrm{H}_{2} \mathrm{O}_{2}$ & $3: 2: 1.5$ & 240 & $4: 00$ & Yellow \\
8 & $\mathrm{HNO}_{3}: \mathrm{HClO}_{4}: \mathrm{H}_{2} \mathrm{O}_{2}$ & $3: 2: 1$ & 240 & $4: 35$ & Clear light yellow \\
9 & $\mathrm{HNO}_{3}: \mathrm{HClO}_{4}$ & $5: 1$ & 300 & $3: 00$ & Clear \& colorless (optimized) \\
10 & $\mathrm{HNO}_{3}: \mathrm{HClO}_{4}$ & $3: 2$ & 300 & $3: 10$ & Cloudy suspension \\
\hline
\end{tabular}

*The bold font indicates optimum conditions.

maximum signal intensity of the instrument. Hallow cathode lamp for each metal operated at the manufacturer's recommended conditions were used at its respective primary source line and therefore the solutions were successively aspirated into the flame. The acetylene-air flow was managed to make ensure suitable flame conditions. The measurements were conducted in a triplicate on each sample. The metals were determined by absorption/concentration mode then, the instrument readout was recorded for every sample solution manually. The same analytical procedure was employed for the determination of metals within the seven blank solutions [17] [27]. The operating conditions for FAAS employed for each analyte are given in Table S1.

The results obtained from FAAS were in $\mathrm{mg} / \mathrm{L}$, but it was converted into $\mathrm{mg} / \mathrm{kg}$ (dry mass) by using the following equation.

$$
\text { Concentration }(\mathrm{mg} / \mathrm{L})=\frac{\text { Concentration }(\mathrm{mg} / \mathrm{L}) \times V}{W}
$$

where, $W$ is the weight in $\mathrm{g}$ of the sample, and $V$ is the final volume of solution [28].

\section{Instrumental Calibration}

The instrument was calibrated using five series of working standards for each metal of interest. The working standard solutions of each metal were prepared freshly from $10 \mathrm{mg} / \mathrm{L}$ intermediate standard solutions of their respective metals. Concentrations of the working standards, value of the correlation coefficients of the calibration curve and equations for calibration curves of each metal are listed in Table S2. From the correlation coefficients in Table S2 it is possible to say that, the change in absorbance with the concentration of each metal was in a good positive correlation and linearly fit.

Method of Performance and Method of Validation 


\section{Method Detection Limit (MDL)}

MDL is that the minimum amount of analyte which will be measured and reported within $99 \%$ confidence level that the analyte concentration is greater than zero [29]. In other words, it is the minimum amount of analyte which will be distinguished from statistical fluctuations in a blank, usually correspond to the signal of blank and three times the standard deviation of the sample blank [30]. In the present study, Seven blank samples were digested following an equivalent procedure as the teff samples and each of the blank samples were analyzed for metal concentrations of $\mathrm{Na}, \mathrm{K}, \mathrm{Mg}, \mathrm{Ca}, \mathrm{Mn}, \mathrm{Zn}, \mathrm{Fe}, \mathrm{Cu}, \mathrm{Pb}$ and $\mathrm{Cd}$ by FAAS. The standard deviations for each metal were calculated from the seven blank triplicate measurements to work out method detection limit of the instrument. Then the method detection limit of each metal was calculated as three times the standard deviation of the blank ( $\left.3 \mathrm{~S}_{\text {blank }}, \mathrm{n}=21\right)$ (Table 3$)$.

\section{Method Quantification Limits (MQL)}

MQL is the lowest concentration at which a measurement is quantitatively meaningful. It is also commonly defined as 10 times the signal/noise ratio. If the noise is approximated as the standard deviation of the blank $\left(\mathrm{S}_{\text {blank }}\right)$, then MQL is $10 \times \mathrm{S}_{\text {blank }}, \mathrm{n}=21$ [18] [31]. The results in Table 3 have revealed that both MDL and MQL values were greater than the IDL; hence, the result of analysis could be reliable.

\section{Recovery Tests}

Analytical method is suitable when it's validated for its intended purpose. Due to the absence of certified reference material for the samples within the laboratory, the optimized digestion procedure was validated by spiking the samples with a typical of known concentration of the analyte metals and therefore the efficiency of the optimized procedure was checked. The spiked samples were digested in triplicate following an equivalent digestion procedure developed for

Table 3. Instrument detection limit, method detection limit and quantification limit for metals of interest determined in teff samples.

\begin{tabular}{cccc}
\hline Metal & IDL $(\mathrm{mg} / \mathrm{kg})$ & MDL $(\mathrm{mg} / \mathrm{kg})$ & MQL $(\mathrm{mg} / \mathrm{kg})$ \\
\hline $\mathrm{K}$ & 0.010 & 0.0549 & 0.1749 \\
$\mathrm{Mg}$ & 0.001 & 0.1144 & 0.3642 \\
$\mathrm{Ca}$ & 0.010 & 0.0807 & 0.2568 \\
$\mathrm{Na}$ & 0.002 & 0.0542 & 0.1725 \\
$\mathrm{Mn}$ & 0.001 & 0.0067 & 0.0215 \\
$\mathrm{Zn}$ & 0.005 & 0.0229 & 0.0730 \\
$\mathrm{Fe}$ & 0.030 & 0.0617 & 0.1965 \\
$\mathrm{Cu}$ & 0.020 & 0.0468 & 0.1492 \\
$\mathrm{~Pb}$ & 0.100 & 0.1159 & 0.3691 \\
$\mathrm{Cd}$ & 0.005 & 0.0107 & 0.0341 \\
\hline
\end{tabular}

$\mathrm{IDL}=$ Instrument detection limit, $\mathrm{MDL}=$ Method detection limit for teff sample, $\mathrm{MQL}=$ Method quantification limit for Teff. 
teff sample. The digested spiked samples were analyzed for respective metals using FAAS (Table 4). Finally, \% recovery decided by using recovery formula [32].

$$
\% \text { Recovery }=\frac{C_{m} \text { in spiked sample }-C_{m} \text { in nonspiked sample }}{C_{m} \text { added for spiking }} \times 100
$$

where: $C_{m}$ is the concentration of metals in the sample.

\section{Statistical Analysis}

Data obtained from laboratory entry management and preliminary summaries were done on Microsoft excel spreadsheet. All analyses were administered in triplicate and therefore the data was presented as mean \pm standard deviations. Differences between treatments of means were done by using analysis of variance (ANOVA). For comparison of the means of treatments, the Fisher's least significant difference (LSD) test was used at $\alpha=0.05$ significance level. Linear correlations coefficient $(r)$ were determined using the Pearson product-moment correlation. All statistical analysis was done using SAS 9.1.3 windows version software program [33].

\section{Results and Discussions}

\section{Concentration of Metals in Teff Samples}

The results indicated that the samples had variable concentration of analyte metals in three types of teff from the three districts. Among the analyzed metals, cadmium was below the method detection limit. The results determined from each sampling sites were listed in terms of mean value and standard deviation of $\mathrm{mg} / \mathrm{kg}$ dry weight (Table 5).

\section{Distribution Patterns of Metals in Different Teff Samples}

There was a variation in macro-essential metals concentration in three teff types (Table 6). The concentration of $\mathrm{K}$ was the highest of all the major metals and ranges from 2879.3 - $3074.7 \mathrm{mg} / \mathrm{kg}$ dry weight followed by $\mathrm{Mg}(2463.9$ $2555.2 \mathrm{mg} / \mathrm{kg}$ dry weight) while $\mathrm{Na}(82.3-109.7 \mathrm{mg} / \mathrm{kg}$ dry weight) was the least

Table 4. Recovery test for the optimized procedure of teff samples and \%RSD.

\begin{tabular}{cccccc}
\hline Metal & $\begin{array}{c}\text { Conc. In sample } \\
(\mathrm{mg} / \mathrm{L})\end{array}$ & Amount added (mg/L) & \multicolumn{3}{c}{ Conc. in spiked } \\
sample $(\mathrm{mg} / \mathrm{L})$ & $\begin{array}{c}\text { Amount recovered } \\
(\mathrm{mg} / \mathrm{L})\end{array}$ & Recovery (\%) \\
\hline $\mathrm{Na}$ & $84.3 \pm 1.7$ & 200 & $302.1 \pm 0.85$ & 217.8 & $108.9 \pm 2.64$ \\
$\mathrm{~K}$ & $2882.9 \pm 3.7$ & 200 & $3089.1 \pm 3.2$ & 206.2 & $103.1 \pm 0.93$ \\
$\mathrm{Mg}$ & $2479.2 \pm 4.2$ & 200 & $2672.5 \pm 7.1$ & 193.3 & $96.7 \pm 3.08$ \\
$\mathrm{Ca}$ & $1352.6 \pm 10.4$ & 200 & $1539.6 \pm 6.5$ & 187.0 & $93.5 \pm 3.48$ \\
$\mathrm{Mn}$ & $56.1 \pm 0.2$ & 200 & $238.3 \pm 1.1$ & 182.2 & $91.1 \pm 0.44$ \\
$\mathrm{Cu}$ & $42 \pm 3.5$ & 200 & $258.7 \pm 4.5$ & 216.7 & $108.4 \pm 0.52$ \\
$\mathrm{Zn}$ & $45.2 \pm 6.2$ & 200 & $254.3 \pm 7.4$ & 209.1 & $104.6 \pm 2.1$ \\
$\mathrm{Fe}$ & $223 \pm 1.1$ & 200 & $412.3 \pm 0.5$ & 189.3 & $94.7 \pm 0.76$ \\
$\mathrm{~Pb}$ & $0.130 \pm 0.002$ & 200 & $213.1 \pm 0.002$ & 200.8 & $106.4 \pm 0.20$ \\
$\mathrm{Cd}$ & $\mathrm{ND}$ & - & - & - & - \\
\hline
\end{tabular}


Table 5. Concentration of metals (Mean $\pm \mathrm{SD}, \mathrm{n}=3 \mathrm{in} \mathrm{mg} / \mathrm{kg}$ dry weight) in white, brown and red teff from Soro, Abesehege and Wera districts.

\begin{tabular}{|c|c|c|c|c|c|c|c|c|c|c|c|}
\hline \multirow{2}{*}{ District } & \multirow{2}{*}{$\begin{array}{c}\text { Types of } \\
\text { Teff }\end{array}$} & \multicolumn{10}{|c|}{ Metals } \\
\hline & & $\mathrm{Ca}$ & $\mathrm{Mg}$ & $\mathrm{Na}$ & $\mathrm{K}$ & $\mathrm{Fe}$ & Mn & $\mathrm{Zn}$ & $\mathrm{Cu}$ & $\mathrm{Pb}$ & $\mathrm{Cd}$ \\
\hline \multirow[t]{3}{*}{ Soro } & Brown & $1211 \pm 4.47$ & $2469 \pm 4.6$ & $88 \pm 1.5$ & $2948 \pm 3.2$ & $214 \pm 0.5$ & $68 \pm 0.6$ & $38 \pm 0.00$ & $6.7 \pm 1.3$ & $0.121 \pm 0.002$ & ND \\
\hline & Red & $1739 \pm 30.5$ & $2552 \pm 3.2$ & $90 \pm 0.8$ & $3071 \pm 3.7$ & $232 \pm 2.4$ & $58 \pm 0.7$ & $85 \pm 2.3$ & $16 \pm 0.7$ & $0.12 \pm 0.002$ & ND \\
\hline & White & $1242 \pm 8.31$ & $2467 \pm 3.1$ & $94 \pm 1.7$ & $2902 \pm 3.7$ & $212 \pm 1.1$ & $71 \pm 0.8$ & $35 \pm 8$ & $41 \pm 0.7$ & $0.128 \pm 0.002$ & ND \\
\hline \multirow[t]{3}{*}{ Abeshege } & Brown & $1382 \pm 13.7$ & $2485 \pm 2.1$ & $95 \pm 1.5$ & $3007 \pm 3.7$ & $234 \pm 3.7$ & $56 \pm 0.2$ & $62 \pm 8.1$ & $42 \pm 3.5$ & $0.128 \pm 0.002$ & ND \\
\hline & Red & $1489 \pm 2.98$ & $2507 \pm 4.3$ & $96 \pm 2.9$ & $2956 \pm 7.4$ & $239 \pm 0.9$ & $99 \pm 1.1$ & $42 \pm 3.6$ & $27 \pm 1.8$ & $0.121 \pm 0.002$ & ND \\
\hline & White & $1408 \pm 5.17$ & $2478 \pm 6.2$ & $98 \pm 0.8$ & $2896 \pm 1.8$ & $212 \pm 1.1$ & $62 \pm 0.4$ & $79 \pm 6.8$ & $25 \pm 1.3$ & $0.127 \pm 0.002$ & ND \\
\hline \multirow{3}{*}{ Wera } & Red & $1696 \pm 9.07$ & $2508 \pm 8$ & $106 \pm 3.7$ & $2979 \pm 14.8$ & $217 \pm 11.4$ & $67 \pm 4.0$ & $45 \pm 6.2$ & $22 \pm 2.4$ & $0.123 \pm 0.002$ & ND \\
\hline & LSD & 27.5 & 11.35 & 3.34 & 10.8 & 8.2 & 2.65 & 11.2 & 3.35 & 0.04 & - \\
\hline & $\mathrm{CV}$ & 1.11 & 0.265 & 2.05 & 0.212 & 2.17 & 2.25 & 12.04 & 8.31 & 1.72 & - \\
\hline
\end{tabular}

${ }^{*} \mathrm{ND}=$ not detected, $\mathrm{LSD}=$ least significant difference, $\mathrm{CV}=$ coefficient of variation.
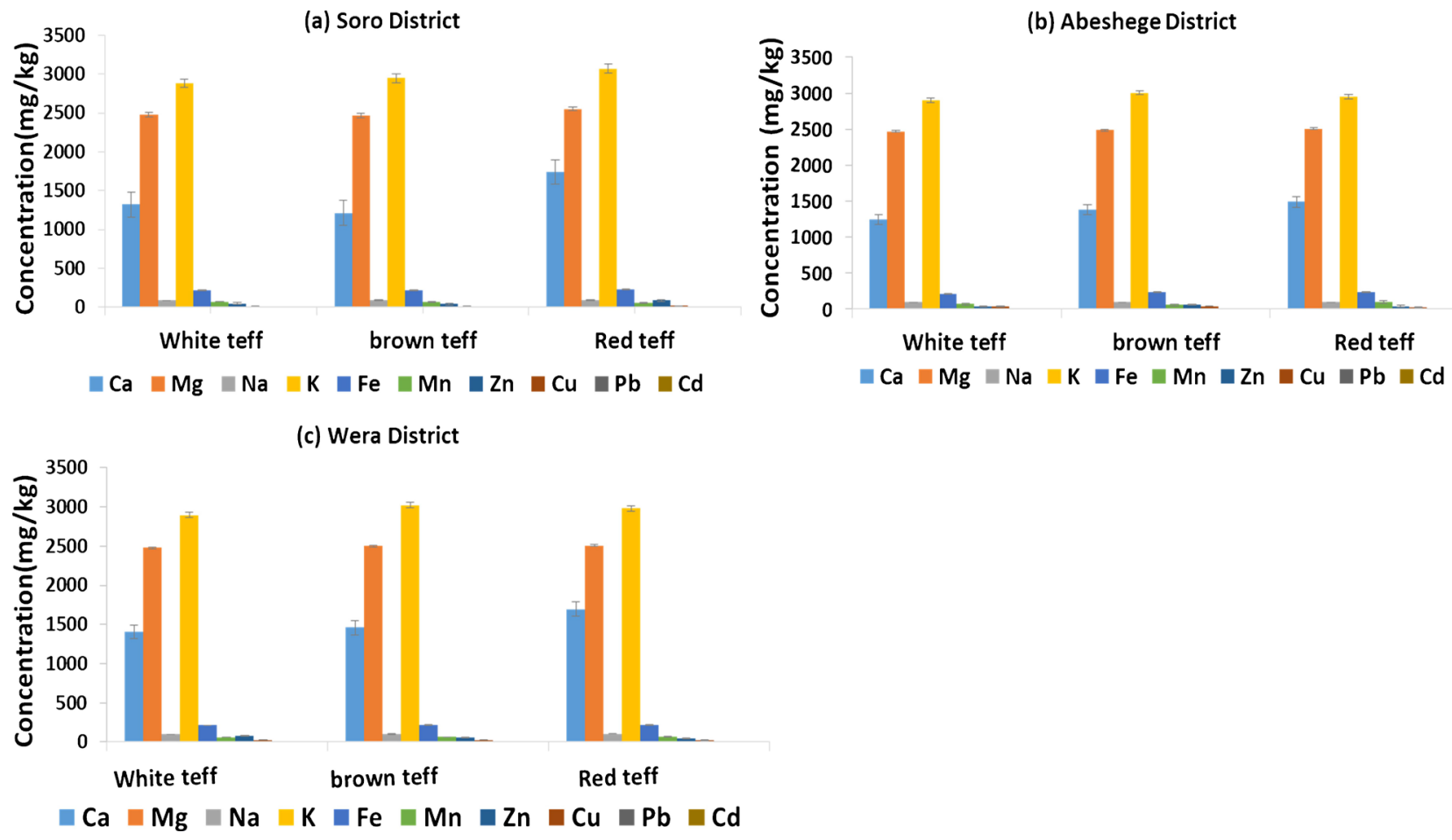

Figure 2. Concentrations of Metals in the white, brown and red teff samples of (a) Soro district, (b) Abeshege district, (c) Wera district.

one among the macro-essential minerals. Briefly, the concentration profile of macro-essential metals determined in teff was $\mathrm{K}>\mathrm{Mg}>\mathrm{Ca}>\mathrm{Na}$.

The higher levels of potassium and magnesium in teff are probably due to the fact that nutrient elements such as $\mathrm{N}, \mathrm{P}, \mathrm{K}, \mathrm{S}$, and $\mathrm{Mg}$ are highly mobile in the 
Table 6. Ranges of metals concentration in three teff types (in $\mathrm{mg} / \mathrm{kg}$ ).

\begin{tabular}{ccccc}
\hline \multirow{2}{*}{ Metal } & \multicolumn{2}{c}{ Ranges of metal concentration $(\mathrm{mg} / \mathrm{kg})$} & \multirow{2}{*}{ Overall range $(\mathrm{mg} / \mathrm{kg})$} \\
\cline { 2 - 4 } & White & Brown & Red & \\
\hline $\mathrm{Na}$ & $82.3-98.8$ & $86.5-103.8$ & $89.2-109.7$ & $82.3-109.7$ \\
$\mathrm{~K}$ & $2879-2906$ & $2944.8-3024.7$ & $2948.6-3074.7$ & $2879-3074.7$ \\
$\mathrm{Mg}$ & $2464-2483$ & $2464.4-2512.5$ & $2502.7-2555.2$ & $2464-2555.2$ \\
$\mathrm{Ca}$ & $1234-1413$ & $1206.5-146.5$ & $1486-1769.5$ & $1206.5-1769.5$ \\
$\mathrm{Fe}$ & $211.7-213$ & $213.5-237.7$ & $205.6-239.9$ & $205.6-239.9$ \\
$\mathrm{Mn}$ & $61.6-71.8$ & $55.8-68.6$ & $57.3-100.1$ & $55.8-100.1$ \\
$\mathrm{Zn}$ & $27-85.8$ & $38-70.1$ & $38.4-87.3$ & $27-87.3$ \\
$\mathrm{Cu}$ & $6.42-41.7$ & $5.4-45.5$ & $15.3-28.8$ & $5.4-45.5$ \\
$\mathrm{~Pb}$ & $0.122-0.130$ & $0.119-0.130$ & $0.118-0.125$ & $0.118-0.130$ \\
$\mathrm{Cd}$ & $\mathrm{ND}$ & $\mathrm{ND}$ & $\mathrm{ND}$ & $\mathrm{ND}$ \\
\hline
\end{tabular}

$\mathrm{ND}=$ not detected

plant tissue and trans-located from old plant tissue to new plant tissue [34]. The other probable reasons for a higher concentration of $\mathrm{K}, \mathrm{Mg}$ and $\mathrm{Ca}$ is if the soil that has been used for cultivating the plant, are highly fertilized with manure and organic residues, they were high in available potassium, calcium and magnesium. Hence, the plant has high amount of these metals [35].

From the level of essential trace metals, Fe $(205.6-239.9 \mathrm{mg} / \mathrm{kg})$ was the most accumulated trace metal followed by $\mathrm{Mn}(55.8-100.1 \mathrm{mg} / \mathrm{kg})$ and $\mathrm{Zn}(27-87.3$ $\mathrm{mg} / \mathrm{kg})$ while $\mathrm{Cu}(5.4-45.5 \mathrm{mg} / \mathrm{kg})$ took the lowest level in teff samples. The highest concentration of Fe may be attributed to its higher levels in the soil [17] [36].

The level of non-essential heavy metals, $\mathrm{Pb}$, detected in teff samples was in the range of $0.118-0.13 \mathrm{mg} / \mathrm{kg}$ and that of $\mathrm{Cd}$, was found to be below the method detection limit. In general the concentration pattern of metals in teff was observed as $\mathrm{K}>\mathrm{Mg}>\mathrm{Ca}>\mathrm{Fe}>\mathrm{Na}>\mathrm{Mn}>\mathrm{Zn}>\mathrm{Cu}>\mathrm{Pb}$ (Figure 2, Table 5). Similarly, the levels of a given metal vary with types of teff. The concentration of all metals except $\mathrm{Cu}$ and $\mathrm{Pb}$ was highest in red teff varieties while the lowest values vary from metal to metal in different types of teff. The highest level of metals in red teff might be attributed to its genetic potential to absorb and accumulate these metals.

The uptake of metals by plants is taking place through different complex biochemical processes. These up taking processes vary based on the ability of the plants to absorb metals from the soil, the availability of the minerals in the soluble and usable forms, the abundance of particular minerals at the particular areas, the degree of contamination of the soil with heavy metals, etc. The differences in the levels of metals in soil arise mainly due to pollution of the biosphere resulting from the rapid industrialization and modern large scale agricultural activities, i.e. use of different types of fertilizers, pesticides, herbicides and other chemicals [18]. 


\section{Comparison of Individual Metals Status in Different Types of Teff Calcium}

Analysis of variance showed that the mean concentration of Ca was significantly $(p<0.05)$ different among the three types of teff and in the sample sites (Table 5). The highest value $(1738.5 \pm 30.5 \mathrm{mg} / \mathrm{kg})$ was detected in red teff from Sore district followed by the same type of teff from Wera district. The lowest level $(1211 \pm 4.47 \mathrm{mg} / \mathrm{kg})$ of Ca was recorded from brown teff of Soro followed by white teff of Abeshege district. Fisher's combined probability test using the LSD criterion for significance indicated that the mean concentration of $\mathrm{Ca}$ in red teff significantly $(\mathrm{p}<0.05)$ higher than brown and white teff. In red teff, there was significant $(\mathrm{p}<0.05)$ difference in the mean concentration of calcium in three sample areas where the maximum and minimum level of Ca were recorded from Soro and Abeshege districts, respectively. Similarly, the mean concentration of $\mathrm{Ca}$ in brown and white teff was significantly $(\mathrm{p}<0.05)$ different over the three locations where the highest levels of $\mathrm{Ca}$ were recorded from Wera district for both types of teff. While, the lowest values of $\mathrm{Ca}$ for both teff types were recorded from Soro district (Table 5).

The variation on the level of Ca with differences on the types of teff and location might be attributed to genetic difference of the teff types to absorb the metals from the soil and accumulate in their tissues and also differences on soil conditions and agronomic practices carried out in this site. In addition to the genetic properties of crop numerous factors such as climatic conditions, soil characteristics and agronomic management practices influence the concentration of metals in plant tissues [37].

The concentration of $\mathrm{Ca}(1206.9-1769.5 \mathrm{mg} / \mathrm{kg})$ in this study agrees with the range of the value $(124-155 \mathrm{mg} / 100 \mathrm{~g})$ reported by [14]. However, lower than the value $(1800 \mathrm{mg} / \mathrm{kg})$ reported by [38] and the value (168.64 \pm 11.03 to $180.7 \pm$ $14.65 \mathrm{mg} / 100 \mathrm{~g})$ reported by [24]. But, it is higher than the values $(83.85 \pm 0.78$ $\mathrm{mg} / 100 \mathrm{~g}$ and $116.15 \pm 0.35 \mathrm{mg} / 100 \mathrm{~g}$ ) for white and brown teff respectively as reported by [39].

\section{Magnesium}

Magnesium was the second most accumulated essential metal in the teff next to $\mathrm{K}$ (Table 6 ). The mean concentration of $\mathrm{Mg}$ was significantly $(\mathrm{p}<0.05)$ varied among the three types of teff over the three locations (Table 5). The highest $(2551.5 \pm 3.2 \mathrm{mg} / \mathrm{kg})$ and lowest $(2467.3 \pm 3.1 \mathrm{mg} / \mathrm{kg})$ concentration of $\mathrm{Mg}$ were recorded from Soro for Red type of teff and Abeshege district for white type of teff, respectively (Table 5). There was significant difference in the mean concentration of $\mathrm{Mg}$ in three types of teff in the three districts. The mean concentration of $\mathrm{Mg}$ in red teff from Soro district was significantly higher than Abeshege and Wera districts. But, there was no significant difference in the mean concentration of $\mathrm{Mg}$ in red teff in Abeshege and Wera districts. The mean concentration of $\mathrm{Mg}$ in brown teff from Wera district was significantly higher than Abeshege and Soro districts. While, the mean concentration of $\mathrm{Mg}$ in brown teff from $\mathrm{Ab}$ eshege district was significantly higher than Soro district. Also, the mean con- 
centration of $\mathrm{Mg}$ in white teff from Abeshege district was significantly lower than Soro and Wera districts. However, there is no significant difference in the mean concentrations of metals in Soro and Wera districts. Such differences might be related to the environmental conditions of the study areas and the characteristics of the teff varieties. Differences in the environmental conditions and crop inherent potential to take nutrient from the soil resulted in the differences on their metabolic activities like accumulations of different metals in their body [40].

The concentrations of $\mathrm{Mg}$ found in this study ranges from 2464 - 2555.2 $\mathrm{mg} / \mathrm{kg}$ dry weight which was higher than the value $(153.16 \pm 9.45$ to $173.7 \pm 8.89$ $\mathrm{mg} / 100 \mathrm{~g})$ reported by [19] and the value $(1840 \mathrm{mg} / \mathrm{kg})$ reported by [38]. The results of this study are in agreement with the study conducted by [39].

\section{Sodium}

The concentration of Sodium in the studied teff samples ranged from 82.3 $109.7 \mathrm{mg} / \mathrm{kg}$ dry weight which showed a significant $(\mathrm{p}<0.05)$ difference over locations for the three types of teff (Table 5). The higher concentration of $\mathrm{Na}$ was found in red teff from Wera district and the lower concentration was observed in white teff from Soro district (Table 5). The concentration of sodium was relatively lower than other macro essential metals in this study. The mean concentration of $\mathrm{Na}$ in white teff from Soro district was significantly higher than Abeshege and Wera districts. The mean concentration of $\mathrm{Na}$ in white teff from Wera district was significantly higher than Abeshege and Soro districts. The mean concentration of $\mathrm{Na}$ in brown teff from Abeshege district was significantly higher than the Soro district. The mean concentration of $\mathrm{Na}$ in red teff from Wera district was significantly higher than Abeshege and Soro districts. Also, the mean concentration of $\mathrm{Na}$ in red teff from Abeshege district was significantly higher than Wera district.

The range of mean concentration of $\mathrm{Na}$ in this study $(82.3-109.7 \mathrm{mg} / \mathrm{kg}$ dry weight) was higher than the values $2.32 \pm 0.35$ and $2.85 \pm 0.20 \mathrm{mg} / 100 \mathrm{~g}$ for white and brown teff respectively, as reported by [39]. But, lower than the value (22.06 $25.68 \mathrm{mg} / 100 \mathrm{~g})$ reported by [19] and the value ( $150 \mathrm{mg} / \mathrm{kg})$ reported by [38].

\section{Potassium}

Potassium was the most accumulated metal in teff with the mean concentration ranges from $2879-3074.7 \mathrm{mg} / \mathrm{kg}$. Analysis of variance showed that the mean concentration of $\mathrm{K}$ was significantly $(\mathrm{p}<0.05)$ different among teff types as well as locations (Table 5). The highest level of $\mathrm{K}(3070.9 \pm 3.7 \mathrm{mg} / \mathrm{kg})$ was observed in Soro district red teff and the lowest $(2882.9 \pm 3.7 \mathrm{mg} / \mathrm{kg})$ concentration was found in Soro district white teff. The higher concentration of $\mathrm{K}$ in the teff may be due to its higher abundance in the soil. The addition of $\mathrm{K}$ fertilizers to the soils rapidly increases the concentration of available $\mathrm{K}$ that could be attributed to mineralization of organic matter, the solubilization effect of rain water and due to increased chemical and biological fixation of potassium in the presence of fertilizers [35]. 
The mean concentration of $\mathrm{K}$ in white teff from Soro district was significantly $(\mathrm{p}<0.05)$ lower than Abeshege and Wera districts. However, there was no significant difference in Abeshege and Wera districts. The mean concentration of $\mathrm{K}$ in brown teff from Wera district was significantly $(\mathrm{p}<0.05)$ higher than Abeshege and Soro districts. The mean concentration of $\mathrm{K}$ in brown teff from Abeshege district was significantly $(\mathrm{p}<0.05)$ higher than that in Soro district. The mean concentration of $\mathrm{K}$ in red teff from Soro district was significantly $(\mathrm{p}<$ $0.05)$ higher than Abeshege and Wera districts. The mean concentration of $\mathrm{K}$ in red teff from Wera district was significantly higher than Abeshege district.

The range of mean concentration of $\mathrm{K}(2879-3074.7 \mathrm{mg} / \mathrm{kg})$ in this study was higher than the result $(198.7-230.8 \mathrm{mg} / 100 \mathrm{~g})$ reported by [19] while lower than the reported values $(486.80 \pm 8.48 \mathrm{mg} / 100 \mathrm{~g})$ for brown teff, $383.70 \pm 3.25$ $\mathrm{mg} / 100 \mathrm{~g}$ for white teff [39] and the mean concentration of $(4270 \mathrm{mg} / \mathrm{kg})$ as reported by [38].

\section{Iron}

Analysis of variance showed that the mean concentration of Fe was significantly $(\mathrm{p}<0.05)$ different among three teff types (Table 5$)$. The highest mean concentration $(238.6 \pm 0.9 \mathrm{mg} / \mathrm{kg})$ was observed in red teff from Abeshege district followed by the same type of teff from Soro district. The lowest mean concentration $(211.7 \pm 1.1 \mathrm{mg} / \mathrm{kg})$ was found in white teff from Wera district followed by the same type of teff from Abeshege district. Fisher's combined probability test using the LSD criterion for significance indicated that the mean concentration of $\mathrm{Fe}$ in red teff is significantly $(\mathrm{p}<0.05)$ higher than that in brown and white teffs. There was no significant difference in the mean concentration of $\mathrm{Fe}$ in white and brown teff in all sample sites. The mean concentration of $\mathrm{Fe}$ in red teff from Wera district was significantly $(\mathrm{p}<0.05)$ lower than Abeshege and Soro districts. However, there is no significant difference in the mean concentrations of Fe in red teff in Soro and Abeshege districts.

The concentration of Fe was found to be the highest of all trace essential metals measured in teff samples. The mean concentration of $\mathrm{Fe}$ in this study varies from $205.6-239.9 \mathrm{mg} / \mathrm{kg}$. The pattern of mean concentration of Fe in teff varieties was in the order of red $>$ brown $>$ white in the sample sites. The concentration range of $\mathrm{Fe}$ obtained in this study was in agreement with the range of values (14.1 $-27.1 \mathrm{mg} / 100 \mathrm{~g})$ reported by [19] and lower than the value reported by [14].

The mean concentration of $\mathrm{Fe}$ in teff samples of this study ranges from 205.6 $239.9 \mathrm{mg} / \mathrm{kg}$, which was below the maximum permissible level of $425.5 \mathrm{mg} / \mathrm{kg}$ set by [41].

\section{Manganese}

The mean concentration of Manganese in teff was ranged from $55.8-100.1$ $\mathrm{mg} / \mathrm{kg}$ dry weight which showed significant $(\mathrm{p}<0.05)$ difference over locations for the three types of teff (Table 5). The highest level of Mn was observed in red teff from Abeshege district sample and the lowest concentration was found in brown teff from Abeshege district (Table 5). Fisher's combined probability test 
using the LSD criterion for significance indicated that there was significance $(\mathrm{p}<$ 0.05) difference in the mean concentration of $\mathrm{Mn}$ in three types of teff. The mean concentration of $\mathrm{Mn}$ in red teff from Abeshege district was significantly ( $\mathrm{p}$ $<0.05)$ higher than that in Soro and Wera districts. Also, the mean concentration of $\mathrm{Mn}$ in red teff from Wera district was significantly $(\mathrm{p}<0.05)$ higher than in Soro district. The mean concentration of $\mathrm{Mn}$ in brown teff from Soro district was significantly higher than Abeshege and Wera districts. Similarly, the mean concentration of $\mathrm{Mn}$ in brown teff from Wera district was significantly ( $\mathrm{p}<$ 0.05) higher than Abeshege district. The mean concentration of $\mathrm{Mn}$ in white teff from Abeshege district was significantly $(\mathrm{p}<0.05)$ higher than Soro and Wera districts. Also, the mean concentration of $\mathrm{Mn}$ in white teff from Soro district was significantly higher than Wera district.

The result $(55.8-100.1 \mathrm{mg} / \mathrm{kg})$ of $\mathrm{Mn}$ in this study was in agreement with the range of value $(4.84-22.36 \mathrm{mg} / 100 \mathrm{~g})$ reported by [19]. The concentration of $\mathrm{Mn}$ in this study was below maximum permissible level $500 \mathrm{mg} / \mathrm{kg}$ dry weight set by [41].

\section{Zinc}

The mean concentration of $\mathrm{Zn}$ in teff was ranged from $27-87.3 \mathrm{mg} / \mathrm{kg}$ dry weight. The highest level $(84.7 \pm 2.3 \mathrm{mg} / \mathrm{kg})$ of $\mathrm{Zn}$ was observed in red teff of Soro district and the lowest $(35.1 \pm 8 \mathrm{mg} / \mathrm{kg})$ concentration was found in white teff of Abeshege district. Fisher's combined probability test using the LSD criterion for significance indicated that there was significant $(p<0.05)$ difference in the mean concentration of $\mathrm{Zn}$ in three types of teff in the three districts (Table $5)$. The mean concentration of $\mathrm{Zn}$ in red teff from Soro district was significantly $(\mathrm{p}<0.05)$ higher than that in Abeshege and Wera districts. Also, the mean concentration of $\mathrm{Zn}$ in red teff from Abeshege district was significantly $(\mathrm{p}<0.05)$ higher than that in Wera districts. The mean concentration of $\mathrm{Zn}$ in brown teff from Abeshege district was significantly $(\mathrm{p}<0.05)$ higher than Soro and Wera districts. Similarly, the mean concentration of $\mathrm{Zn}$ in brown teff from Wera district was significantly $(\mathrm{p}<0.05)$ higher than of Soro districts. The mean concentration of $\mathrm{Zn}$ in white teff from Wera district was significantly higher than that in Abeshege and Soro districts. Also, the mean concentration of $\mathrm{Zn}$ in white teff from Soro district was significantly higher than Abeshege districts with $\mathrm{p}<0.05$.

The concentration range of $\mathrm{Zn}(27-87.3 \mathrm{mg} / \mathrm{kg})$ in this study was higher than the value $(2.98-4.79 \mathrm{mg} / 100 \mathrm{~g})$ reported by [19] and the value $(36.3 \mathrm{mg} / \mathrm{kg}) \mathrm{re}-$ ported by [38]. The mean concentration of $\mathrm{Zn}$ in this study ranges from $27-87.3$ $\mathrm{mg} / \mathrm{kg}$ dry weight which was below maximum permissible level $99.4 \mathrm{mg} / \mathrm{kg}$ dry weight set by [7].

\section{Copper}

The concentration of $\mathrm{Cu}$ in this study varies from $5.4-45.5 \mathrm{mg} / \mathrm{kg}$ dry weight. The highest concentration $(42 \pm 3.5 \mathrm{mg} / \mathrm{kg}$ ) of Cu was observed in brown teff in the Abeshege district and the lowest level $(6.7 \pm 1.3 \mathrm{mg} / \mathrm{kg})$ was found in brown teff in the Soro district. Analysis of variance revealed that the mean concentration of Copper was significantly different among teff types in the sample dis- 
tricts. Fisher's combined probability test using the LSD criterion for significance indicated that the mean concentration of $\mathrm{Cu}$ in white teff from Abeshege district was significantly $(p<0.05)$ higher than that in Soro and Wera districts. Also, the mean concentration of $\mathrm{Cu}$ in white teff from Wera district was significantly ( $\mathrm{p}<$ 0.05) higher than Soro district. Similarly, the mean concentration of $\mathrm{Cu}$ in brown teff from Abeshege district was significantly $(\mathrm{p}<0.05)$ higher than Soro and Wera districts. The mean concentration of $\mathrm{Cu}$ in brown teff from Wera district was significantly $(\mathrm{p}<0.05)$ higher than Soro district. Also, the mean concentration of $\mathrm{Cu}$ in red teff from Abeshege district was significantly $(\mathrm{p}<0.05)$ higher than that in Soro and Wera districts. The mean concentration of $\mathrm{Cu}$ in red teff from Wera district was significantly $(\mathrm{p}<0.05)$ higher than Soro district.

The mean concentration of $\mathrm{Cu}(5.4-45.5 \mathrm{mg} / \mathrm{kg})$ in this study was higher than the value $(1.08-2.51 \mathrm{mg} / 100 \mathrm{~g})$ reported by [19] and the value $(8.1 \mathrm{mg} / \mathrm{kg})$ reported by [38]. The permissible limit of copper for human consumption recommended by $\mathrm{FAO} / \mathrm{WHO}$ is $73.3 \mathrm{mg} / \mathrm{kg}$ [42]. The present investigation revealed that the concentration of $\mathrm{Cu}$ was below the maximum permissible limit 73.3 $\mathrm{mg} / \mathrm{kg}$ for human health set by [41].

Lead

In this study, the concentration of lead in teff ranged from $0.118-0.130$ $\mathrm{mg} / \mathrm{kg}$ dry weights. The highest $(0.128 \pm 0.002 \mathrm{mg} / \mathrm{kg})$ concentration of $\mathrm{Pb}$ was found in white teff from Abeshege district and the lowest $(0.12 \pm 0.002 \mathrm{mg} / \mathrm{kg})$ concentration of $\mathrm{Pb}$ was detected in red teff from the Soro district. One-way Analysis of variance revealed that the mean concentration of $\mathrm{Pb}$ was significantly different among teff types in the sample districts. Fisher's combined probability test using the LSD criterion for significance indicated that the mean concentration of $\mathrm{Pb}$ in white teff from Abeshege district was significantly $(\mathrm{p}<0.05)$ higher than that in Soro and Wera districs. The mean concentration of $\mathrm{Pb}$ in white teff from Wera district was significantly $(p<0.05)$ higher than Soro districts. The mean concentration of $\mathrm{Pb}$ in brown teff from Soro district was significantly $(\mathrm{p}<$ $0.05)$ lower than Abeshege and Wera districts. However, there was no significant difference in brown teff from Abeshege and Wera districts with $p<0.05$. The mean concentration of $\mathrm{Pb}$ in red teff from Wera district was significantly $(\mathrm{p}<$ 0.05) higher than Soro and Abeshege districts. Also, the mean concentration of $\mathrm{Pb}$ in red teff from Abeshege district was significantly $(\mathrm{p}<0.05)$ higher than that in Soro district.

The concentration of $\mathrm{Pb}(0.118-0.13 \mathrm{mg} / \mathrm{kg})$ in this study was lower than the value $(0.05 \mathrm{mg} / 100 \mathrm{~g})$ reported by [39]. The concentration of lead observed in teff in this study was below the recommended limit $0.3 \mathrm{mg} / \mathrm{kg}$ as set by [41].

\section{Cadmium}

The level of cadmium in teff varieties of all sample districts was below the method detection limit indicating that there is no Cd contamination.

\section{Pearson Correlation of Metals}

In this study, to correlate the effect of one metal concentration on the concentration of another metal, the Pearson correlation matrices using correlation 
coefficient ( $\mathrm{r}$ ) for the samples were used and presented in Table 7.

In the teff samples analyzed for the metal levels, the correlation was strong (close to \pm 1 ) for some metals, moderate (around \pm 0.5 ) for some other metals and weak $(< \pm 0.5)$ for the remaining metals. The poor relationship may be due to the fact that different soil types, environmental conditions and capacity of the plant to accumulate specific metal.

There was strong positive correlation between $\mathrm{Mg}$ with (Ca and $\mathrm{K}$ ). Moderate positive correlations were seen between $\mathrm{Ca}$ with $\mathrm{K}, \mathrm{Mg}$ with (Fe and $\mathrm{Zn}$ ), $\mathrm{K}$ with $\mathrm{Fe}$ and $\mathrm{Cu}$ with $\mathrm{Pb}$. Metals interact with other metals in the uptake process by the plants. This is because of some metals have similar properties. For example, $\mathrm{Mn}$ shows properties of both the alkaline earth cations such as $\mathrm{Mg}^{2+}$ and $\mathrm{Ca}^{2+}$ and the heavy metals $(\mathrm{Zn}, \mathrm{Fe})$ [43]. This could be the probable reason for positive correlation for $\mathrm{Mg}$ with ( $\mathrm{Ca}$ and $\mathrm{K}$ ), $\mathrm{Ca}$ with $\mathrm{K}, \mathrm{Mg}$ with ( $\mathrm{Fe}$ and $\mathrm{Zn}$ ), $\mathrm{K}$ with $\mathrm{Fe}$ and $\mathrm{Cu}$ with $\mathrm{Pb}$ which may be arise from common anthropogenic or natural sources as well as from similarity in chemical properties.

Weak positive correlation was seen between $\mathrm{Na}$ with $(\mathrm{Mg}, \mathrm{K}, \mathrm{Zn}$ and $\mathrm{Pb}$ ); $\mathrm{Fe}$ with ( $\mathrm{Mn}$ and $\mathrm{Zn}$ ); $\mathrm{Cu}$ with (K, $\mathrm{Fe}$ and $\mathrm{Zn}$ ); $\mathrm{Pb}$ with $\mathrm{Zn}$. Moderate negative correlation has been observed between $\mathrm{Mg}$ with $\mathrm{Pb}$ and $\mathrm{Mn}$ with $\mathrm{Zn}$. Weak negative correlation was recognized between $\mathrm{Na}$ with $\mathrm{Fe}$; $\mathrm{Mn}$ with $(\mathrm{Ca}, \mathrm{Mg}, \mathrm{Na}, \mathrm{K}, \mathrm{Cu}$ and $\mathrm{Pb}$ ); $\mathrm{Cu}$ with ( $\mathrm{Ca}$ and $\mathrm{Mg}) ; \mathrm{Pb}$ with $(\mathrm{Ca}, \mathrm{K}$, and $\mathrm{Fe})$. The weak positive or negative correlation indicated that the presence or absence of one metal has an effect to a lesser extent on the other.

\section{Conclusions}

The contents of all essential and non-essential metals in the three teff varieties of present study were within the recommended level. However, the level of toxic metals such as $\mathrm{Pb}$ was below the permissible limit and that of $\mathrm{Cd}$ was below the method detection limit. Hence, it is safe for daily human consumption. So that this study helped to provide information on that the consumption of these teffs

Table 7. Pearson's correlation matrices of metals for teff samples.

\begin{tabular}{cccccccccc}
\hline & $\mathrm{Ca}$ & $\mathrm{Mg}$ & $\mathrm{Na}$ & $\mathrm{K}$ & $\mathrm{Fe}$ & $\mathrm{Mn}$ & $\mathrm{Zn}$ & $\mathrm{Cu}$ & $\mathrm{Pb}$ \\
\hline $\mathrm{Ca}$ & 1 & & & & & & & & \\
$\mathrm{Mg}$ & $0.890^{* *}$ & 1 & & & & & & & \\
$\mathrm{Na}$ & $0.435^{*}$ & 0.142 & 1 & & & & & & \\
$\mathrm{~K}$ & $0.663^{* *}$ & $0.758^{* *}$ & 0.281 & 1 & & & & & \\
$\mathrm{Fe}$ & $0.409^{*}$ & $0.553^{* *}$ & -0.041 & $0.526^{* *}$ & 1 & & & & \\
$\mathrm{Mn}$ & -0.093 & -0.050 & -0.041 & -0.325 & 0.264 & 1 & & & \\
$\mathrm{Zn}$ & $0.483^{*}$ & $0.511^{* *}$ & 0.059 & $0.445^{*}$ & 0.161 & $-0.542^{* *}$ & 1 & & \\
$\mathrm{Cu}$ & -0.071 & -0.140 & $0.417^{*}$ & 0.061 & 0.228 & -0.042 & 0.029 & 1 & \\
$\mathrm{~Pb}$ & $-0.388^{*}$ & $-0.541^{* *}$ & 0.147 & -0.347 & -0.352 & -0.288 & 0.029 & $0.606^{* *}$ & 1 \\
\hline
\end{tabular}

${ }^{* *}$ Correlation is significant at the 0.01 level (2-tailed); ${ }^{*}$ Correlation is significant at the 0.05 level (2-tailed). 
serves as a good dietary source for the treatment of different health complications.

A statistical analysis of variance at $95 \%$ confidence level revealed that there were significant differences in the mean concentrations of all metals between the three types of teff and teff from the three grown districts. This could be attributed to the difference in mineral contents of soil, agricultural practices or the extent of mineral absorption by teff varieties. The value of Pearson correlation coefficient revealed strong positive correlation between $\mathrm{Mg}$ with ( $\mathrm{Ca}$ and $\mathrm{K}$ ), the rest have moderate or weak positive or negative correlation of metals with each other in teff.

Experimental investigations indicated that the Red teff contains higher amount of essential metals than brown and white teffs. It also contains higher amount of iron relative to brown and white teff kinds. Therefore, based on the results Red teff can be considered as a good source for prevention of iron deficiency especially for infants and pregnant woman.

\section{Authors' Contributions}

AH collected, analyzed and interpreted the data, which was part of his MSC thesis of Analytical Chemistry at Wolaita Sodo University, Ethiopia. AL supervised data collection and interpretation; helped to draft the manuscript as well as approved the final manuscript. MB and CK revised the final manuscript. The final manuscript has been approved by all authors.

\section{Availability of Data and Materials}

Data generated during this research work can be available upon request.

\section{Conflicts of Interest}

The authors declare no conflicts of interest regarding the publication of this paper.

\section{References}

[1] Ketema, S. (1993) Tef (Eragrostis Tef), Breeding, Agronomy, Genetic Resources, Utilization and Role of Ethiopian Agriculture. Institute of Agricultural Research, $102 \mathrm{p}$.

[2] Stallknecht, G.F., Gilbertson, K.M. and Eckhoff, J.L. (1993) Tef: Food Crop for Humans and Animals. In: Jamick, J. and Simon, J.E., Eds., New Crops, Wiley, New York, 231-234.

[3] Baye, K. (2014) Teff: Nutrient Composition and Health Benefits. International Food Policy Development Research, 67.

[4] Central Statistical Agency (CSA) (2017) Agricultural Sample Survey: Report on Area and Production for Crops. Stat. Bull. No. 388, 1-26.

[5] Chondie, Y.G. and Bekele, A. (2017) Adaptability Evaluation and Selection of Improved Tef Varieties in Growing Areas of Southern Ethiopia. Hydrology: Current Research, 8, 266. https://doi.org/10.4172/2157-7587.1000266 
[6] Corke, H., Wrigley, C., Seetharaman, K. and Faubion, J. (2016) The Cereal Grains: Teff Overview. In: Encyclopedia of Food Grains, the World of Food Grains, 2nd Edition, Elsevier, Oxford, 209-220. https://doi.org/10.1016/B978-0-12-394437-5.00018-8

[7] Girma, A. and Meareg, A. (2017) Determination of the Iron Content of Soil and Cultivated White Teff from Parzete and Zeghi Kebele, Debatie Woreda Metekel Zone, Benshangul Gumuz, Ethiopia. International Journal of Innovative Pharmaceutical Sciences \& Research, 5, 11-32.

[8] Gebretsadik, Z. and Berhe, T. (2010) Increasing the Productivity of Tef: New Approaches with Dramatic Results. 1-52.

[9] Ketema, S. (1997) Tef (Eragrostis Tef (Zucc.) Trotter). Promoting the Conservation and Use of Underutilized and Neglected Crops Series No. 12. Institute of Plant Genetics and Crop Plant Research, Gatersleben and Int. Plant Genetic Resources Institute, Rome, 52.

[10] Narasimha, H.V. and Urga, K. (1997) Effect of Natural Fermentation on the HCl-Extractability of Minerals from Tef (Eragrostis Tef). Bulletin of the Chemical Society of Ethiopia, 11, 3-10. https://doi.org/10.4314/bcse.v11i1.21007

[11] Ebba, T. (1960) Tef (Eragrostis Tef): The Cultivation Usage and Some of the Known Diseases and Insect Pests. Part 1. Expt. Station Bulletin College of Agriculture Dire Dawa, Ethiopia. 60.

[12] Mengesha, M. (1966) Chemical Composition of Teff (Eragrostis Tef) Compared with That of Wheat, Barley and Grain Sorghum. Economic Botany, 20, 268-273. https://doi.org/10.1007/BF02904277

[13] Zelalem, T. (2006) Levels of Trace Cadmium and Essential Zinc in Wheat Flour Commercially Available in Addis Ababa, Ethiopia. MSc Thesis, Addis Ababa University, Addis Ababa, 1-40.

[14] Alemtsehay, B., Abebe, Y., Hambidge, K.M., Stoecker, B.J., Bailey, K. and Gibson, R.S. (2007) Phytate, Zinc, Iron and Calcium Content of Selected Raw and Prepared Foods Consumed in Rural Sidama, Southern Ethiopia, and Implications for Bioavailability. Journal of Food Composition and Analysis, 20, 161-168. https://doi.org/10.1016/j.jfca.2006.09.003

[15] El-Alfy Taha, S., Shahira, M.E. and Amani, A.S. (2012) Chemical and Biological Study of the Seeds of Eragrostis Tef (Zucc.) Trotter. Natural Product Research, 26, 619-629. https://doi.org/10.1080/14786419.2010.538924

[16] Eyob, M. and Ali, M. (2015) Determination of the Levels of Iron from Red, Mixed and White Tef (Eragrostis) Flour by Using Uv/Visible Spectrometry. Journal of Natural Sciences Research, 5, 34-41.

[17] Yohannes, W. and Chandravanshi, B.S. (2015) Levels of Essential and Non-Essential Metals in Ginger (Zingiber officinale) Cultivated in Ethiopia. SpringerPlus, 4, 1-13. https://doi.org/10.1186/s40064-015-0899-5

[18] Chandravanshi, B.S. and Adane, A. (2017) Levels of Essential and Non-Essential Metals in the Raw Seeds and Processed Food (Roasted Seeds and Bread) of Maize/Corn (Zea mays L.) Cultivated in Selected Areas of Ethiopia. Bulletin of the Chemical Society of Ethiopia, 31, 185-199. https://doi.org/10.4314/bcse.v31i2.1

[19] Zeleke, K. (2009) Levels of Essential Elements in Three Tef (Eragrostis Tef (Zucc.) Trotter) Varieties. MSc Thesis, Addis Ababa University, Addis Ababa, 1-76.

[20] Abeshege Wereda Rural Development Office AWARDO (2015) Annual Report for 2014, Abeshege Woreda of Gurage Zone SNNPR. Annual Report for 2014. 12.

[21] Kibemo, D. (2011) Farmers' Perception on Soil Erosion and Their Use of Structural 
Soil Conservation Measures in Soro District, Southern Ethiopia. MSc Thesis, Addis Ababa University, Addis Ababa, 1-93.

[22] IPMS/ILRI (2005) Alaba Pilot Learning Site Diagnosis and Program Design (Unpublished). Addis Ababa.

[23] Amsalu, B. (2008) Determinants of Farmers' Innovativeness in Alaba Special Woreda, Southern Nations, Nationalities and Peoples Region, Ethiopia. MSc Thesis, Haramaya University, Haramaya, 1-145.

[24] Ma, L.Q. and Chen, M. (2001) Comparison of Three Aqua-Regia Digestion Methods for Twenty Florida Soils. Soil Science Society of America Journal, 65, 491-499. https://doi.org/10.2136/sssaj2001.652491x

[25] Bell, R., Huang, L., Dell, B. and Woodward, J. (2004) Rapid Nitric Acid Digestion of Plant Material with an Open-Vessel Microwave System. Communication Soil Science Plant Analysis, 35, 427-440. https://doi.org/10.1081/CSS-120029723

[26] Chandravanshi, B.S. and Feleke, D. (2015) Levels of Major and Trace Elements in Fennel (Foeniculumn vulgari Mill) Fruits Cultivated in Ethiopia. Springerplus, 4, 5. https://doi.org/10.1186/2193-1801-4-5

[27] Braithwaite, A., Wilson, B. and Pyatt, F.B. (2005) An Evaluation of Procedures for the Digestion of Soils and Vegetation from Areas with Metalliferous Pollution. Toxicological \& Environmental Chemistry, 87, 335-344. https://doi.org/10.1080/02772240500165570

[28] Wodaje, A. and Alemayehu, A. (2017) Determination of Heavy Metal Concentration in Soils Used for Cultivation of Allium sativum L. (Garlic) in East Gojjam Zone, Amhara Region, Ethiopia. Cogent Chemistry, 3, Article ID: 1419422.

[29] Harris, D.C. (1982) Quantitative Chemical Analysis. 4th Edition, W.H. Freeman and Company, New York, 84.

[30] Butcher, D.J. and Sneddon, J.A. (1998) Practical Guide to Graphite Furnace Atomic Absorption Spectrometry. John Wiley and Sons, New York, 34-149.

[31] Teressa, B. and Alemyehu, A. (2017) Determination of the Levels of Essential and Non-Essential Metals in of Enset (Enset ventricosum) and Soil Sample. International Journal of Modern Chemistry and Applied Science, 4, 518-525.

[32] Mitra, S. (2003) Sample Preparation Techniques in Analytical Chemistry. John Wiley and Sons Inc., Hoboken, Vol. 162, 227-244. https://doi.org/10.1002/0471457817

[33] SAS Institute Inc. (2002) SAS/STAT Users Guide. Version 8. SAS Software, Cary, 8.

[34] Chandravanshi, B.S., Mesfin, R. and Minalshewa, A. (2010) Concentration Levels of Essential and Non-Essential Metals in Ethiopian Khat (Catha edulis Forsk). Biological Trace Element Research, 138, 316-325. https://doi.org/10.1007/s12011-010-8617-1

[35] Watson Weeraratna, C.S. and Wettasingha, D.T. (1977) Effect of Mineralization of Tea Prunings on Some Soil Characteristics. Plant and Soil, 46, 93-99. https://doi.org/10.1007/BF00693116

[36] Chandravanshi, B.S. and Birhanu, M. (2015) Levels of Selected Essential and Non-Essential Metals in Seeds of Korarima (Aframomum corrorima) Cultivated in Ethiopia. Brazilian Journal of Food Technology, 18 102-111. https://doi.org/10.1590/1981-6723.5614

[37] Dominguez-Perles, R., Martínez-Ballesta, M.C., Moreno, D.A., Muries, B., Alcaraz-López, C., Bastías, E., García-Viguera, C. and Carvajal, M. (2010) Minerals in Plant Food: Effect of Agricultural Practices and Role in Human Health. A Review. 
Agronomy for Sustainable Development, 30, 295-309.

https://doi.org/10.1051/agro/2009022

[38] United States Department of Agricultural (USDA) (2016) National Nutrient Database for Standard Reference; Release 28. Basic Report No. 20142, USDA, Washington DC. https://ndb.nal.usda.gov/ndb/foods/show/6592?1-133

[39] Kibatu, G. (2017) Determination of Major, Minor and Trace Elements in Tef Using Portable Total X-Ray Fluorescence (TXRF) Spectrometer. EC Nutrition, 9, 51-59.

[40] Ncube, B., Finnie, J.F. and Van Staden, J. (2012) Quality from the Field: The Impact of Environmental Factors as Quality Determinants in Medicinal Plants. South African Journal of Botany, 82, 11-20. https://doi.org/10.1016/j.sajb.2012.05.009

[41] FAO/WHO (2001) Codex Alimentarius Commission, Food Additives and Contaminants, Joint FAO/WHO Food Standard Program. 1-300.

[42] Wodaje, A. (2015) Assessment of Some Heavy Metals Concentration in Selected Cereals Collected from Local Markets of Ambo City, Ethiopia. Journal of Cereals and Oilseeds, 6, 8-13. https://doi.org/10.5897/JCO15.0138

[43] Adane, D. and Almaz, A. (2015) Profile of Essential and Non-Essential Metals in Soil and Khat (Catha Edulis Forsk) Leaves Cultivated in Southern Regional, Ethiopia. American Journal of Physical Chemistry, 4, 58-64.

https://doi.org/10.11648/j.ajpc.20150406.13 


\section{Supporting Information}

Table S1. Instrument operating conditions for the determination of metals in teff samples using FAAS.

\begin{tabular}{ccccccc}
\hline Element & $\lambda(\mathrm{nm})$ & $\mathrm{SW}(\mathrm{nm})$ & $\mathrm{IDL}(\mathrm{mg} / \mathrm{L})$ & $\mathrm{LC}(\mathrm{mA})$ & PMT $(\mathrm{V})$ & Energy $(\mathrm{J})$ \\
\hline $\mathrm{K}$ & 767 & 0.7 & 0.010 & 2 & 262.2 & 3.222 \\
$\mathrm{Mg}$ & 285.2 & 0.7 & 0.001 & 1 & 344.6 & 3.934 \\
$\mathrm{Ca}$ & 423 & 0.7 & 0.010 & 2 & 178.6 & 3.912 \\
$\mathrm{Na}$ & 589 & 0.2 & 0.002 & 2 & 228.0 & 3.722 \\
$\mathrm{Mn}$ & 280 & 0.7 & 0.001 & 3 & 175.6 & 3.752 \\
$\mathrm{Zn}$ & 214 & 0.7 & 0.005 & 2 & 234.1 & 3.276 \\
$\mathrm{Fe}$ & 248 & 0.2 & 0.030 & 7 & 219.4 & 3.434 \\
$\mathrm{Cu}$ & 325 & 0.7 & 0.020 & 1.5 & 194.6 & 3.816 \\
$\mathrm{~Pb}$ & 283.2 & 0.7 & 0.100 & 2 & - & 3.501 \\
$\mathrm{Cd}$ & 228.9 & 0.7 & 0.005 & 2 & 166.8 & 3.142 \\
\hline
\end{tabular}

$\mathrm{PMT}=$ photomultiplier tube, $\mathrm{SW}=$ slit width, $\lambda=$ wave length, $\mathrm{LC}=$ lamp current, $\mathrm{IDL}=$ Instrument detection limit.

Table S2. Working standard concentration, correlation coefficient and equations of the calibration curves for the determination of metals using FAAS.

\begin{tabular}{cccc}
\hline Metal & $\begin{array}{c}\text { Concentrations of working } \\
\text { standards }(\mathbf{m g} / \mathrm{L})\end{array}$ & $\begin{array}{c}\text { Correlation coefficient of } \\
\text { the calibration curves }\end{array}$ & $\begin{array}{c}\text { Equation for calibration } \\
\text { curve }\end{array}$ \\
\hline $\mathrm{Na}$ & $0.25,0.5,0.75,1,1.25$ & 0.9987 & $\mathrm{~A}=0.0684 \mathrm{C}-0.0013$ \\
$\mathrm{~K}$ & $0.25,0.5,1,1.5,2$ & 0.9990 & $\mathrm{~A}=0.0312 \mathrm{C}-0.007$ \\
$\mathrm{Mg}$ & $5,10,15,20,25$ & 0.9992 & $\mathrm{~A}=0.0816 \mathrm{C}-0.265$ \\
$\mathrm{Ca}$ & $5,10,15,20,25$ & 0.9981 & $\mathrm{~A}=0.0387 \mathrm{C}-0.1187$ \\
$\mathrm{Mn}$ & $0.25,0.5,0.75,1,1.25$ & 0.9981 & $\mathrm{~A}=0.2768 \mathrm{C}-0.0634$ \\
$\mathrm{Cu}$ & $0.11,0.25,0.3,0.35,0.4$ & 0.9992 & $\mathrm{~A}=0.0869 \mathrm{C}-0.0025$ \\
$\mathrm{Zn}$ & $0.1,0.25,0.5,0.75,1$ & 0.9995 & $\mathrm{~A}=0.0893 \mathrm{C}-0.001$ \\
$\mathrm{Fe}$ & $0.5,1,2,3,4$ & 0.9986 & $\mathrm{~A}=0.19 \mathrm{C}+0.0897$ \\
$\mathrm{~Pb}$ & $0.15,0.25,0.35,0.45,0.55$ & 0.9959 & $\mathrm{~A}=0.027 \mathrm{C}-0.0031$ \\
$\mathrm{Cd}$ & $0.15,0.25,0.45,0.55,0.95$ & 0.9976 & $\mathrm{~A}=0.1588 \mathrm{C}-0.0253$ \\
\hline
\end{tabular}

$\mathrm{A}=$ Absorbance, $\mathrm{C}=$ Concentration. 